\title{
A Matemática Financeira nos Mestrados Profissionais em Ensino: uma revisão da
} Literatura

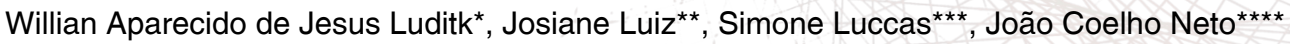

\section{Resumo}

O presente artigo objetiva identificar quais os Produtos Educacionais que vem sendo produzidos em Mestrados Profissionais em Ensino envolvendo a temática da Matemática e da Educação Financeira e ainda quais metodologias e recursos estão sendo utilizados para o ensino dos referidos conteúdos. Esta pesquisa assume cunho qualitativo e natureza procedimental bibliográfica, utilizando para tal uma adaptação dos passos da Revisão Sistemática de Literatura, tendo sido consultados os repositórios online dos respectivos programas de Mestrado Profissional em Ensino avaliados pela Coordenação de Aperfeiçoamento de Pessoal de Nível Superior no quadriênio de 2017. Após a análise, foi possível identificar que dos 4.417 trabalhos iniciais, somente 45 tratavam da temática pesquisada, ou seja, aproximadamente $1,04 \%$ do total. Outro fator identificado foi o de que o conteúdo de Matemática Financeira é apresentado nas produções atrelado a situações cotidianas dos alunos referenciando compra e venda de produtos, financiamentos, empréstimos entre outras atividades oportunizando-os experienciar situações que os tornem consumidores mais conscientes. Ao fim, 22,22\% (10 trabalhos) das produções trazem a Sequência Didática como Produto Educacional, 33,33\% (15 trabalhos) criaram um conjunto de atividades ou Sequência de Atividades, $11,11 \%$ ( 5 trabalhos) desenvolveram um curso ou um minicurso relacionado a temática, 6,66\% (3 trabalhos) dos trabalhos tratam de um Guia Didático, $4,4 \%$ ( 2 trabalhos) Jogos Educacionais e o restante (10 trabalhos) estão divididos entre CartiIhas, Coletânea de Estudos, Material Textual de Apoio, Livretos, E-books, Planilhas Eletrônicas, Proposta Metodológica de Ensino, Ambiente Virtual, Tutorial para o uso da calculadora HP 12C, Unidade de Ensino e Aprendizagem Gamificada.

Palavras-chave: Ensino; Mestrados Profissionais; Educação Financeira; Matemática Financeira; Revisão Sistemática de Literatura.

\footnotetext{
- Graduado em Licenciatura em Matemática - UENP. Mestrando em Ensino pela Universidade Estadual do Norte do Paraná. E-mail: willianluditk@gmail.com

* Mestranda em Ensino da Universidade Estadual do Norte do Paraná. E-mail: professorajosianeluiz@gmail.com

*** Professora do Centro de Ciências Humanas e da Educação e do Programa de Pós-Graduação em Ensino da Universidade Estadual do Norte do Paraná. E-mail: simoneluccas@uenp.edu.br

..*.* Professor e Pesquisador do Programa de Pós-Graduação em Ensino e do Centro de Ciências Humanas e da Educação da Universidade Estadual do Norte do Paraná - campus de Cornélio Procópio. E-mail: joaocoelho@ uenp.edu.br
} 


\section{Introdução}

A Matemática Financeira atualmente encontra-se presente no cotidiano populacional em diversas questões, tais como: Qual forma de pagamento é mais vantajosa, à vista ou a prazo? Qual o financiamento ideal para a compra de um imóvel? Como funciona a cobrança de juros de um empréstimo bancário? Dentre outras. Assim, diante da incorporação da Matemática Financeira na sociedade atual, surge a necessidade de uma formação mais ampla e completa desta temática. Haja vista ainda que "[...] uma pessoa completamente formada possui a responsabilidade de administrar a sua vida financeira e, muita das vezes, a de toda família" (FARIAS, 2013, p. 13).

Outro aspecto a citar-se no que se refere à importância da Matemática Financeira está no fato de que

[...] qualquer exemplo que tomemos dela é de adaptação imediata para a realidade do aluno. A interdisciplinaridade na Matemática Financeira também ocorre de maneira natural dentro da própria Matemática ou mesmo com outras áreas do conhecimento, como a História e as Ciências Sociais (FARIAS, 2013, p. 13).

Neste contexto trabalhos como em Silva (2017), argumentam que a cada momento o professor deve reinventar a sua forma de ensinar, adicionando novas metodologias que despertem interesse no aluno de uma forma bem divertida. Nesse sentido Martins (2016) propõe o uso de calculadoras e de planilhas eletrônicas para ensinar Matemática Financeira por meio de uma Sequência Didática, utilizando conteúdos básicos de juros simples e juros compostos. Também é necessário ressaltar a importância de capacitar os alunos a serem consumidores conscientes, tomando decisões adequadas quanto à compra e venda de bens e serviços, sabendo assim administrar suas próprias finanças e de forma simples e ágil exercer a função social do ensino.

Uma outra área da matemática em ascensão é a Educação Financeira, pois em conformidade com o Decreto 7.397, em que apresenta a Estratégia Nacional de Educação Financeira (ENEF):

[...] educação financeira é fundamental para que o cidadão aprenda a importância das finanças no seu cotidiano e possa usar racionalmente seus recursos para obter e melhorar a qualidade de vida, para tanto, o trabalho é focado na formação do aluno no que diz respeito à educação financeira (BRASIL, 2010, p. 1).

Apesar da relevância da temática, Rocha e Mariani (2019, p. 226) argumentam que 
Apesar da importância e da complexidade desse tema, bem como sua conexão com o ensino de Matemática, poucos estudos tomam como campo de pesquisa a comunidade escolar e consideram princípios da Educação Financeira de estudantes, professores e da sociedade na tomada de decisão, como apontam Campos (2013), Almeida (2015), Pessoa (2016), Schünemann (2016), Rocha (2017), Pessoa, Muniz e Kistemann Jr (2018).

Diante da relevância desta temática, mas analogamente da escassez de produções tangentes a Matemática Financeira e Educação Financeira, surgiu-nos uma inquietação quanto as produções relativas a estas áreas, em especial aos trabalhos desenvolvidos nos Programas de Mestrado Profissional da área de Ensino, tendo em vista também a nossa inserção em um programa desta natureza. A despeito destes programas, tem que a Coordenação de Aperfeiçoamento de Pessoal de Nível Superior (CAPES) por meio da Portaria $\mathrm{n} \square .47 / 1995$, em outubro daquele ano determinou a implementação para a avaliação e acompanhamento de cursos de mestrados voltados à formação profissional, passando assim, a existir no Brasil os Mestrados Profissionais em concomitância com os Mestrados Acadêmicos (CAPES, 1995). E assim, a regulamentação desses cursos deu-se por meio da Portaria CAPES 80/1998 (MOREIRA, 2015).

Porém, foi somente no ano de 2002 que surgiram os primeiros programas de Mestrado Profissional em Ensino, os quais visavam a formação continuada dos professores, com enfoque na qualificação didático-pedagógica em uma área específica do conhecimento (REBEQUE; OSTERMANN; VISEU, 2017). Fundamentando a importância desta qualificação, Moreira (2004, p. 133-134) argumenta que: “o mestrado em ensino deverá ter caráter de preparação profissional na área docente focalizando o ensino, a aprendizagem, o currículo, a avaliação e o sistema escolar" para justamente profissionalizar cada vez mais a profissão docente.

Destarte, diante da relevância destas temáticas, bem como da importância das produções oriundas de Programas de Mestrado Profissional da área de Ensino, o presente artigo busca descobrir de que forma o ensino de Matemática Financeira e/ ou de Educação Financeira vêm sendo abordado em Dissertações de Mestrados Profissionais da área de Ensino e quais os produtos que foram criados para facilitar esse processo.

Para a elaboração deste artigo e a análise dos resultados levantados, esta pesquisa foi dividida em quatro seções: a primeira contextualiza os motivos pelos quais a pesquisa foi realizada; a segunda seção apresenta os procedimentos metodológicos; 
a terceira, a apresentação dos resultados e discussões e, a quarta, as considerações finais e perspectivas de trabalhos futuros. Assim, no item a seguir dar-se-á ênfase aos procedimentos metodológicos adotados nesta pesquisa, destacando os materiais e métodos adotados para a pesquisa.

\section{Procedimentos Metodológicos}

Traçando o encaminhamento metodológico dessa pesquisa de cunho qualitativo, de acordo com Flick (2009, p. 23), tem como aspectos essenciais: "[...] a apropriabilidade de métodos e teorias, perspectivas dos participantes e sua diversidade, reflexividade do pesquisador e da pesquisa, variedade de abordagens e de métodos”. No que tange a natureza procedimental, esta pesquisa assume viés bibliográfico que em conformidade com Silva e Menezes (2005, p. 21), constitui uma pesquisa que é "[...] elaborada a partir de material já publicado, constituído principalmente de livros, artigos de periódicos e atualmente com material disponibilizado na Internet".

Desta forma, e com vista a responder ao objetivo deste artigo, esta pesquisa foi estruturada sob o prisma das etapas da Revisão Sistemática da Literatura (RSL), tomando como embasamento teórico Kitchenham et al. (2004) e Biolchini (2005), os quais conceituam este método, e apontam que seu objetivo é “[...] identificar, selecionar, avaliar, interpretar e sumariar estudos disponíveis considerados relevantes para um tópico de pesquisa ou fenômeno de interesse" (apud FELIZARDO et al., 2017, p. 4).

Para coleta de dados desta pesquisa, buscou-se as produções dos Mestrados Profissionais da área de Ensino, visando mapear todas as Dissertações que encontram-se disponíveis de forma online, nos sites dos programas cadastrados e avaliados pela CAPES no último quadriênio no ano de 2017. Logo, o período de busca foi de todos os anos nos quais os programas têm disponíveis em seus respectivos repositórios online.

Assim, com a realização desta Revisão Sistemática de Literatura (RSL) visou-se responder aos seguintes questionamentos:

- $\quad \mathbf{Q}_{\mathbf{1}}$ : Quantas e quais são as Dissertações (de Mestrados Profissionais em Ensino) que abordam a Matemática Financeira e/ ou Educação Financeira como temática central? 
- $\mathbf{Q}_{2}$ : De que forma o conteúdo de Matemática Financeira é abordado nestas Dissertações?

- $\mathbf{Q}_{3}$ : Quais metodologias de ensino e recursos estão sendo utilizados ao se trabalhar com a Matemática Financeira?

Assim, com vista a tentar responder as questões desta RSL foram delimitados alguns procedimentos explicitados a seguir:

- No primeiro momento foram selecionados todos os Programas de Mestrados Profissionais na área de Ensino que haviam sido avaliados pela CAPES no quadriênio do ano de 2017;

- No segundo momento, foram filtrados dentre os Mestrados Profissionais em Ensino, aqueles que tinham como linha de pesquisa o Ensino de Ciências e Matemática, ou seja, que pudessem vir a pesquisar a temática objetivada nesta RSL;

- No terceiro momento foram definidas as palavras-chave de busca, sendo estas, "Matemática Financeira" e "Educação Financeira";

- No quarto momento foi realizada a pesquisa em todos os sites dos Programas de Mestrados Profissionais em Ensino, filtrados na segunda etapa. Buscando nos títulos das Dissertações as palavras-chave definidas;

- Por fim, foi realizada uma leitura das Dissertações visando identificar as informações que pudessem constituir um arcabouço teórico, para responder as questões desta RSL. Cabe ainda ressaltar, que foram adotados como critérios de exclusão os trabalhos que por ventura aparecessem de forma repetida, os quais foram excluídos.

Ao término desta RSL, adotando os critérios acima evidenciados e tendo por intuito responder as questões norteadoras desta pesquisa, foi realizada uma análise interpretativa dos dados coletados, identificando as convergências entre as Dissertações encontradas, bem como as disparidades entre as mesmas. Então, os resultados desta RSL, são evidenciados na seção seguinte.

\section{Resultados e Discussão}

Levando em consideração os critérios enunciados no item anterior, a demonstração dos resultados desta pesquisa relata a preocupação exposta pelos profissionais da área de Matemática Financeira em criar mecanismos para subsidiar o ensino, 
fazendo com que esse processo seja cada vez mais acessível e agradável tanto para os professores quanto para os alunos.

Sendo assim a busca foi realizada com o objetivo de identificar primariamente a forma pela qual o conteúdo de Matemática Financeira é abordado na confecção dos Produtos Educacionais dos Programas de Mestrado Profissional em Ensino, respaldando assim o processo de Educação Financeira. Para tal, precisava-se quantificar e categorizar quais eram estes Programas, para então identificar se os trabalhos produzidos tratavam da temática de Matemática Financeira.

Desta forma, buscando pela base da CAPES segundo a última avaliação realizada, chegou-se a um resultado de 73 programas vigentes de Mestrado Profissional em Ensino. No entanto, alguns destes, não estavam relacionados com o Ensino de Matemática, com o Ensino de Ciências e, nem tampouco com viés Tecnológico, sendo assim subtraídos da análise, restando um total de 52 Programas, conforme disposto no Quadro 1.

Quadro 1 - Programas de Mestrado Profissional em Ensino voltados a temática

(continua...)

\begin{tabular}{|l|l|l|l|r|r|}
\hline$N^{0}$ & \multicolumn{1}{|c|}{ Sigla da IES } & $\begin{array}{c}\text { Área de } \\
\text { Avaliação }\end{array}$ & \multicolumn{1}{|c|}{ Nome do Programa } & $\begin{array}{c}\text { Nota } \\
\text { CAPES }\end{array}$ & $\begin{array}{l}\text { Total de Dissertações } \\
\text { Pesquisadas }\end{array}$ \\
\hline 1 & IFSUL & Ensino & Ciências e Tecnologias na Educação & 3 & 39 \\
\hline 2 & UFPA & Ensino & $\begin{array}{l}\text { Docência em Educação em Ciências e Mate- } \\
\text { mática }\end{array}$ & 4 & 78 \\
\hline 3 & UNESP/BAURU & Ensino & Docência para a Educação Básica & 4 & 125 \\
\hline 4 & UEMS & Ensino & Educação Científica e Matemática & 3 & 44 \\
\hline 5 & IFES & Ensino & Educação em Ciências e Matemática & 3 & 199 \\
\hline 6 & UFRRJ & Ensino & Educação em Ciências e Matemática & 3 & 38 \\
\hline 7 & UFJF & Ensino & Educação Matemática & 4 & 107 \\
\hline 8 & UFOP & Ensino & Educação Matemática & 4 & 120 \\
\hline 9 & USS & Ensino & Educação Matemática & 2 & 112 \\
\hline 10 & IFG & Ensino & Educação para Ciências e Matemática & 4 & 281 \\
\hline 11 & PUC/MG & Ensino & Ensino & 4 & 60 \\
\hline 12 & UENP & Ensino & Ensino & 3 & 109 \\
\hline 13 & URI & Ensino & Ensino Científico e Tecnológico & 4 & 66 \\
\hline 14 & UNIGRANRIO & Ensino & Ensino das Ciências & 4 & 17 \\
\hline 15 & UTFPR & Ensino & Ensino de Ciência e Tecnologia & 5 & 125 \\
\hline 16 & UFMS & Ensino & Ensino de Ciências & 3 & 49 \\
\hline 17 & UNIPAMPA & Ensino & Ensino de Ciências & 3 & 3 \\
\hline 18 & IFRJ & Ensino & Ensino de Ciências & 4 & 3 \\
\hline 19 & UNB & Ensino & Ensino de Ciências & & 60 \\
\hline 20 & UEG & Ensino & Ensino de Ciências & & \\
\hline
\end{tabular}


(conclusão)

\begin{tabular}{|c|c|c|c|c|c|}
\hline 21 & UERR & Ensino & Ensino de Ciências & 4 & 81 \\
\hline 22 & UNIFEI & Ensino & Ensino de Ciências & 3 & 0 \\
\hline 23 & UFOP & Ensino & Ensino de Ciências & 3 & 69 \\
\hline 24 & FUPF & Ensino & Ensino de Ciências e Matemática & 3 & 50 \\
\hline 25 & IFSP & Ensino & Ensino de Ciências e Matemática & 3 & 40 \\
\hline 26 & UNICSUL & Ensino & Ensino de Ciências e Matemática & 5 & 57 \\
\hline 27 & UCS & Ensino & Ensino de Ciências e Matemática & 4 & 40 \\
\hline 28 & UEPB & Ensino & Ensino de Ciências e Matemática & 4 & 128 \\
\hline 29 & UFAL & Ensino & Ensino de Ciências e Matemática & 3 & 20 \\
\hline 30 & UFPEL & Ensino & Ensino de Ciências e Matemática & 4 & 76 \\
\hline 31 & UFU & Ensino & Ensino de Ciências e Matemática & 4 & 66 \\
\hline 32 & UFAC & Ensino & Ensino de Ciências e Matemática & 3 & 98 \\
\hline 33 & UFC & Ensino & Ensino de Ciências e Matemática & 3 & 145 \\
\hline 34 & UNIVATES & Ensino & Ensino de Ciências Exatas & 5 & 151 \\
\hline 35 & UFSCAR & Ensino & Ensino de Ciências Exatas & 3 & 140 \\
\hline 36 & UTFPR & Ensino & $\begin{array}{l}\text { Ensino de Ciências Humanas, Sociais e da } \\
\text { Natureza }\end{array}$ & 4 & 78 \\
\hline 37 & UFMT & Ensino & Ensino de Ciências Naturais & 4 & 95 \\
\hline 38 & UFRN & Ensino & Ensino de Ciências Naturais e Matemática & 4 & 188 \\
\hline 39 & UNICENTRO & Ensino & Ensino de Ciências Naturais e Matemática & 3 & 48 \\
\hline 40 & FURB & Ensino & Ensino de Ciências Naturais e Matemática & 4 & 112 \\
\hline 41 & UDESC & Ensino & Ensino de Ciências, Matemática e Tecnologias & 3 & 70 \\
\hline 42 & UEPA & Ensino & Ensino de Matemática & 3 & 54 \\
\hline 43 & UFRGS & Ensino & Ensino de Matemática & 5 & 162 \\
\hline 44 & UTFPR & Ensino & Ensino de Matemática & 3 & 52 \\
\hline 45 & UERJ & Ensino & Ensino em Educação Básica & 4 & 85 \\
\hline 46 & UFG & Ensino & Ensino em Educação Básica & 3 & 94 \\
\hline 47 & IFAM & Ensino & Ensino Tecnológico & 4 & 69 \\
\hline 48 & UTFPR & Ensino & Formação Científica, Educacional e Tecnológica & 4 & 112 \\
\hline 49 & CPII & Ensino & Práticas de Educação Básica & 4 & 77 \\
\hline 50 & UNIMES & Ensino & Práticas Docentes no Ensino Fundamental & 1 & 56 \\
\hline 51 & UFN & Ensino & Ensino de Ciências e Matemática & 4 & 172 \\
\hline 52 & USP/EEL & Ensino & Projetos Educacionais de Ciências & 3 & 61 \\
\hline \multicolumn{5}{|c|}{ Total Pesquisado } & 4.417 \\
\hline
\end{tabular}

Fonte: CAPES (2017, on-line)

Após esta identificação prévia, todos os Programas acima listados foram acessados, ano por ano, buscando em todas as defesas as produções desenvolvidas com intuito de ensinar Matemática Financeira com o propósito de educar financeiramente. Ao todo foram pesquisados 4.417 (quatro mil quatrocentos e dezessete) produtos 
educacionais e destes, somente 45 (quarenta e cinco) tratavam do ensino destas temáticas, conforme aponta o Quadro 2.

Quadro 2 - Programas com Dissertações referentes à temática pesquisada (Matemática Financeira e/ ou Educação Financeira).

\begin{tabular}{|l|l|l|l|r|}
\hline \multicolumn{1}{|c|}{$N^{0}$} & \multicolumn{1}{|c|}{ Sigla da IES } & $\begin{array}{c}\text { Área de } \\
\text { Avaliação }\end{array}$ & \multicolumn{1}{c|}{ Nome do Programa } & $\begin{array}{r}\text { Dissertações } \\
\text { Encontradas }\end{array}$ \\
\hline 01 & CPII & Ensino & Práticas de Educação Básica & 1 \\
\hline 02 & FUPF & Ensino & Ensino de Ciências e Matemática & 2 \\
\hline 03 & FURB & Ensino & Ensino de Ciências Naturais e Matemática & 4 \\
\hline 04 & IFES & Ensino & Educação em Ciências e Matemática & 1 \\
\hline 05 & IFG & Ensino & Educação para Ciências e Matemática & 1 \\
\hline 06 & UDESC & Ensino & Ensino de Ciências, Matemática e Tecnologias & 1 \\
\hline 07 & UEPA & Ensino & Ensino de Matemática & 1 \\
\hline 08 & UEPB & Ensino & Ensino de Ciências e Matemática & 2 \\
\hline 09 & UFC & Ensino & Ensino de Ciências e Matemática & 7 \\
\hline 10 & UFJF & Ensino & Educação Matemática & 4 \\
\hline 11 & UFN & Ensino & Ensino de Ciências e Matemática & 2 \\
\hline 12 & UFOP & Ensino & Educação Matemática & 3 \\
\hline 13 & UFPA & Ensino & Docência em Educação em Ciências e Matemática & 4 \\
\hline 14 & UFRGS & Ensino & Ensino de Matemática & 1 \\
\hline 15 & UFSCAR & Ensino & Ensino de Ciências Exatas & 1 \\
\hline 16 & UNIGRANRIO & Ensino & Ensino das Ciências & 5 \\
\hline 17 & UNIMES & Ensino & Práticas Docentes no Ensino Fundamental & 1 \\
\hline 18 & UNIVATES & Ensino & Ensino de Ciências Exatas & 45 \\
\hline 19 & URI & Ensino & Ensino Científico e Tecnológico & \\
\hline Total & & & &
\end{tabular}

Fonte: autores (2019).

Conforme evidenciado no Quadro 2, somente 19 (dezenove) Programas apresentaram Dissertações que discorriam do ensino de Matemática Financeira e/ ou Educação Financeira. A seguir, o Quadro 3 apresenta quais são as produções encontradas nos programas listados anteriormente e que apresentam as palavras-chave "Matemática Financeira" e/ ou "Educação Financeira". 
Quadro 3 - Trabalhos envolvidos na temática

(continua...)

\begin{tabular}{|c|c|c|c|c|}
\hline $\mathrm{N}^{0}$ & Título da Dissertação & $\begin{array}{c}\text { Ano } \\
\text { Defesa }\end{array}$ & Autor & Produto Educacional \\
\hline 01 & $\begin{array}{l}\text { Aprendizagem de matemática financeira no ensino médio: uma proposta de } \\
\text { trabalho a partir de planilhas eletrônicas }\end{array}$ & 2008 & Marcelo Salvador Cóser Filho & $\begin{array}{l}\text { Sequência Didática utilizando planilhas eletrô- } \\
\text { nicas }\end{array}$ \\
\hline 02 & $\begin{array}{l}\text { Uma reflexão sobre a importância de inclusão de Educação Financeira na } \\
\text { escola pública }\end{array}$ & 2009 & $\begin{array}{l}\text { Denise Teresinha Brandão } \\
\text { Kern }\end{array}$ & Sequência de atividades \\
\hline 03 & $\begin{array}{l}\text { Uso de tecnologias da informação para a aprendizagem de matemática finan- } \\
\text { ceira em cursos técnicos }\end{array}$ & 2010 & Claiton Regis Timm Marques & $\begin{array}{l}\text { Sequência de atividades com a utilização do } \\
\text { Software Excel }\end{array}$ \\
\hline 04 & $\begin{array}{l}\text { O uso da calculadora HP-12C nas operações de matemática financeira co- } \\
\text { mercial com ênfase na análise de investimento }\end{array}$ & 2011 & Antônio Falcão Neto & Tutorial utilizando a calculadora HP 12C \\
\hline 05 & $\begin{array}{l}\text { Tecnologias informacionais e comunicacionais na educação matemática finan- } \\
\text { ceira: criando cenários de investigação na licenciatura em matemática }\end{array}$ & 2012 & Newton Rodrigues Filho & $\begin{array}{l}\text { Curso de serviços utilizando planilhas e Excel } € \\
\text { a Calculadora HP 12C }\end{array}$ \\
\hline 06 & Introdução à matemática financeira por meio de planilhas eletrônicas & 2012 & Rafael Alberto Gonçalves & Planilhas Eletrônicas \\
\hline 07 & $\begin{array}{l}\text { Uma proposta de curso de serviço para a disciplina matemática financeira: } \\
\text { mediada pela produção de significados dos estudantes de administração }\end{array}$ & 2013 & Dejair Frank Barroso & Curso de serviço \\
\hline 08 & $\begin{array}{l}\text { Metodologia de resolução de problemas: ensino e aprendizagem de conceitos } \\
\text { de matemática financeira no EJA }\end{array}$ & 2013 & Tatiele Fátima Miron & Conjunto de situações-problema \\
\hline 09 & $\begin{array}{l}\text { Educação financeira em aulas de matemática com o uso do fluxo de caixa } \\
\text { pessoal }\end{array}$ & 2014 & Alexsandra Alves Pereira & Guia Didático \\
\hline 10 & Educação financeira e educação matemática: inflação de preços & 2014 & Márcio Carlos Vital & Conjunto de Tarefas \\
\hline 11 & Matemática financeira no ensino médio: um jogo para simulação & 2014 & $\begin{array}{l}\text { Renato Schneider Rivero } \\
\text { Jover }\end{array}$ & Jogo Educacional: Investindo na Vida. \\
\hline 12 & Matemática financeira e cidadania: interlocução, leituras e experiências & 2015 & Ana Luiza Araújo Costa & Minicurso \\
\hline 13 & Matemática financeira no ensino médio: uma proposta metodológica de ensino & 2015 & Bruno Henrique de Oliveira & Proposta metodológica de ensino \\
\hline 14 & Matemática financeira no ensino médio numa perspectiva investigativa & 2015 & $\begin{array}{l}\text { Jackelinne Azevedo Silva dos } \\
\text { Santos }\end{array}$ & $\begin{array}{l}\text { Cartilha Didática para ensinar Matemática Fi } \\
\text { nanceira com o uso do Excel. }\end{array}$ \\
\hline 15 & Educação financeira escolar: a noção de juros & 2015 & Jesus Nazareno Martins Dias & Conjunto de Tarefas \\
\hline 16 & $\begin{array}{l}\text { Matemática financeira e tecnologia: espaços para o desenvolvimento da capa- } \\
\text { cidade crítica dos educandos da educação de jovens e adultos }\end{array}$ & 2015 & Luciano Pecoraro Costa & Livreto de Atividades \\
\hline
\end{tabular}


(continuação...)

\begin{tabular}{|c|c|c|c|c|}
\hline 17 & $\begin{array}{l}\text { Matemática financeira na educação de jovens e adultos: uma proposta de } \\
\text { ensino através da resolução de problemas }\end{array}$ & 2015 & Rita Maria Cargnin & Sequência de atividades \\
\hline 18 & $\begin{array}{l}\text { O movimento das pesquisas em educação matemática financeira escolar de } \\
1999 \text { a } 2005\end{array}$ & 2015 & Rodrigo Martins de Almeida & $\begin{array}{l}\text { Coletânea de Estudos em Educação de Mate- } \\
\text { mática Financeira }\end{array}$ \\
\hline 19 & Educação Financeira no Ensino Fundamental: um bom negócio & 2016 & Adriana de Souza Lima & $\begin{array}{l}\text { SpigMath: ambiente virtual de Educação Finan- } \\
\text { ceira para o Ensino Fundamental }\end{array}$ \\
\hline 20 & $\begin{array}{l}\text { Educação financeira por meio de dados reais: atividades didáticas para a edu- } \\
\text { cação básica }\end{array}$ & 2016 & Ana Carolina Gadotti & Sequência de atividades \\
\hline 21 & $\begin{array}{l}\text { Contribuições da matemática financeira para o ensino Médio: o uso de tributos } \\
\text { em tarefas de sala de aula }\end{array}$ & 2016 & Cláudio Júlio César Pinheiro & Conjunto de Tarefas abordando a tributação. \\
\hline 22 & $\begin{array}{l}\text { Construção de uma sequência didática com situações-problema envolvendo } \\
\text { matemática financeira }\end{array}$ & 2016 & Deivid Geraldo Gimenes & Sequência Didática \\
\hline 23 & $\begin{array}{l}\text { Utilização de práticas pedagógicas diferenciadas no ensino de matemática } \\
\text { financeira: um estudo de caso no instituto maranhense de ensino e cultura } \\
\text { - IMEC }\end{array}$ & 2016 & $\begin{array}{l}\text { lomara de Albuquerque } \\
\text { Madeira Martins }\end{array}$ & $\begin{array}{l}\text { Sequência Didática com o auxílio da Calculado- } \\
\text { ra HP } 12 \text { C E Planilhas Eletrônicas }\end{array}$ \\
\hline 24 & $\begin{array}{l}\text { Atividades de matemática financeira por meio de aprendizagem coletiva nos } \\
\text { anos finais do ensino fundamental }\end{array}$ & 2016 & Juliana Bauer De Oliveira & $\begin{array}{l}\text { Atividades de Matemática Financeira por meio } \\
\text { de Aprendizagem Coletiva }\end{array}$ \\
\hline 25 & $\begin{array}{l}\text { Educação de matemática financeira no ensino médio: uma análise crítica do } \\
\text { custo de vida. }\end{array}$ & 2016 & Rudney da Silva & Guia Didático \\
\hline 26 & $\begin{array}{l}\text { Investigação sobre as contribuições da matemática para o desenvolvimento } \\
\text { da educação financeira na escola }\end{array}$ & 2016 & Samuel Ricardo Raschen & Duas atividades \\
\hline 27 & $\begin{array}{l}\text { A inserção da educação financeira em um curso de serviço de matemática } \\
\text { financeira para graduandos de administração }\end{array}$ & 2016 & Wesley Carminati Teixeira & Curso de Serviço \\
\hline 28 & $\begin{array}{l}\text { O uso do dinheiro como recurso sustentável: uma reflexão para a educação } \\
\text { financeira cidadã. }\end{array}$ & 2017 & Iran Abib Valente da Silva & Jogo Educacional: o dinheiro sustentável \\
\hline 29 & $\begin{array}{l}\text { Educação financeira no Ensino Médio: uma análise a partir da Aprendizagem } \\
\text { Significativa de David Ausubel }\end{array}$ & 2017 & Laercio Villa & Sequência Didática \\
\hline 30 & $\begin{array}{l}\text { Educação financeira e educação matemática: } \\
\text { Inflação de preços no ensino médio }\end{array}$ & 2017 & $\begin{array}{l}\text { Leandro Gonçalves dos } \\
\text { Santos }\end{array}$ & Conjunto de Tarefas \\
\hline 31 & Noções de matemática financeira com foco em educação financeira & 2017 & $\begin{array}{l}\text { Marisa do Carmo Pacoff da } \\
\text { Silva }\end{array}$ & E-book \\
\hline
\end{tabular}


(conclusão)

\begin{tabular}{|c|c|c|c|c|}
\hline 32 & $\begin{array}{l}\text { Investigando uma sequência didática sobre juros compostos para a formação } \\
\text { em educação financeira de alunos do ensino médio }\end{array}$ & 2018 & $\begin{array}{l}\text { Aline Amanda Sousa Lopes } \\
\text { Sodré }\end{array}$ & Sequência Didática \\
\hline 33 & O ensino de matemática financeira e aplicações & 2018 & André Alves Sobreira & Sequência Didática \\
\hline 34 & $\begin{array}{l}\text { Educação de jovens e adultos (EJA) e Saberes matemáticos sob a perspecti- } \\
\text { va Da educação financeira escolar }\end{array}$ & 2018 & Carlos Magno Oliveira Muniz & Conjunto de Tarefas \\
\hline 35 & $\begin{array}{l}\text { Contribuições da gamificação para o ensino e a aprendizagem: uma proposta } \\
\text { de ensino para matemática financeira }\end{array}$ & 2018 & Daniel de Melo Jacobsen & $\begin{array}{l}\text { Unidade de Ensino e Aprendizagem (UEA) } \\
\text { Gamificada elaborada na Plataforma Moodle. }\end{array}$ \\
\hline 36 & A educação matemática crítica na educação financeira & 2018 & Flávia Arlete Lovatti & Guia Didático \\
\hline 37 & $\begin{array}{l}\text { Educação financeira na sala de aula: uma proposta metodológica para o ensi- } \\
\text { no da Matemática no Ensino Médio }\end{array}$ & 2018 & Patrícia Santana de Argôlo & Sequência de atividades \\
\hline 38 & $\begin{array}{l}\text { Educação financeira no Ensino Médio: uma proposta para as aulas de Ma- } \\
\text { temática }\end{array}$ & 2019 & Aline Reissuy de Moraes & Sequência Didática \\
\hline 39 & $\begin{array}{l}\text { Educação financeira crítica: a gestão do orçamento familiar por meio de uma } \\
\text { prática pedagógica na educação de jovens e adultos }\end{array}$ & 2019 & Júlio César Rossetto & Sequência de atividades \\
\hline 40 & $\begin{array}{l}\text { A disciplina de Matemática Financeira nas licenciaturas em Matemática e uma } \\
\text { proposta de formação continuada na perspectiva da Matemática Crítica }\end{array}$ & 2019 & Regimar Alves Ferreira & Curso para Formação Pedagógica \\
\hline 41 & $\begin{array}{l}\text { A matemática financeira e a aprendizagem significativa - possíveis contribui- } \\
\text { ções à educação de jovens e adultos }\end{array}$ & 2019 & Rosa Cristina Vieira Dias & $\begin{array}{l}\text { Material textual de apoio para professores de } \\
\text { matemática da educação de jovens e adultos }\end{array}$ \\
\hline 42 & $\begin{array}{l}\text { Educação financeira: olhar sobre a prática do professor que ensina matemáti- } \\
\text { ca nos anos iniciais do ensino fundamental }\end{array}$ & 2019 & $\begin{array}{l}\text { Sílvia Helena da Silva e } \\
\text { Souza }\end{array}$ & Sequência Didática \\
\hline 43 & $\begin{array}{l}\text { Educação financeira: investigação com uma turma de } 1^{\circ} \text { ano do Ensino Médio } \\
\text { por meio de práticas colaborativas }\end{array}$ & 2019 & Tcharles Schneider & Sequência de atividades \\
\hline 44 & $\begin{array}{l}\text { A matemática financeira na educação de jovens e adultos: possibilidades de } \\
\text { ensino e aprendizagem }\end{array}$ & 2019 & Wellison Gomes Casado & Sequência Didática \\
\hline 45 & $\begin{array}{l}\text { Funções executivas, matemática financeira e previdência social: sequência } \\
\text { didática para formação inicial docente }\end{array}$ & 2020 & Lorena Silva de Andrade Dias & Sequência Didática \\
\hline
\end{tabular}

Fonte: autores (2019) 
Baseando-se nos dados apresentados pelo Quadro 3, dos 4.417 (quatro mil quatrocentos e dezessete) trabalhos iniciais, somente 45 (quarenta e cinco) tratavam da temática primária, ou seja, aproximadamente 1,04\% da amostra, constatando que ainda discute-se pouco nos mestrados Profissionais em Ensino as temáticas de Matemática Financeira e de Educação Financeira, abrindo assim um vasto campo para pesquisa. Observe na sequência a análise sucinta dos trabalhos citados anteriormente.

O primeiro trabalho analisado é o de Cóser Filho (2008), de acordo com o autor, a Matemática Financeira possui várias aplicações técnicas e essas devem sem reforçadas com o auxílio de instrumentos que facilitem o ensino. Propõe a criação de uma Sequência Didática utilizando Planilhas Eletrônicas no qual os materiais didáticos oferecidos para esta, sejam voltados à prática com a utilização de recursos tecnológicos. De acordo com o autor, quando da utilização destes recursos, há um ganho considerável na aprendizagem.

Na sequência tem-se na produção de Kern (2009), apresentando uma discussão acerca de um trabalho com a implementação de uma Sequência de Atividades voltada a inserção da Educação Financeira no Ensino Médio, em específico com uma turma de terceiro ano. Como resultados a autora destaca que a inserção da Educação Financeira na Educação Básica além de uma necessidade, esta oportuniza uma reflexão a respeito do planejamento de vida dos discentes, bem como seus próprios objetivos pessoais.

A Dissertação de Marques (2010) objetiva apresentar a aprendizagem dos conceitos de Matemática Financeira em uma turma de curso técnico em Administração e Contabilidade. Para tal, o autor desenvolveu algumas atividades, as quais foram resolvidas com o auxílio de planilhas. Como resultados o autor infere uma dificuldade no trabalho de Matemática Financeira em cursos técnicos, evidenciando assim uma necessidade de uma preparação anterior no que tange a conceitos de Matemática Básica e uso de planilhas.

Já o trabalho de Falcão Neto (2011), consiste na elaboração de um tutorial de operações fundamentais da Matemática Financeira com a utilização da calculadora HP 12C, com vista para contribuir para o ensino em diferentes níveis de ensino (fundamental, médio e superior). Como resultados o autor cita que o uso adequado deste tutorial oportuniza um avanço na aprendizagem no que tange a Matemática Financeira. 
Agora na Dissertação de Rodrigues Filho (2012), tem-se como produto educacional um Curso de Serviços utilizando Planilhas De Excel e a Calculadora HP 12C. $\mathrm{O}$ autor ainda argumenta em seu trabalho a respeito da importância da utilização de tecnologias informacionais e comunicacionais no ensino de Matemática Financeira, salientando que o Professor deve criar cenários que proporcionem ao aluno a capacidade de pesquisa e investigação, com o auxílio dessas tecnologias.

O trabalho de Gonçalves (2012), investiga o uso de planilhas eletrônicas no ensino de Matemática Financeira. Como resultado o autor indica que o uso deste recurso amplia as possibilidades de aplicação da matemática sendo que o limite é a criatividade na sua utilização. A educação pode contribuir nesse processo, utilizando esses recursos em sua dinâmica de ensino e aprendizagem.

O produto educacional de Barroso (2013) envolve a criação de um curso de serviço. O objetivo é apresentar aos leitores um meio alternativo de entender a Matemática Financeira sem o apoio de calculadores e planilhas eletrônicas, destinados não somente a estudantes, mas a qualquer cidadão que queira aprender conceitos financeiros e que possa melhorar suas decisões na hora de consumir. Questões bem pertinentes ao tema como consumo compulsivo e desnecessário, endividamento e problemas financeiros são abordados durante o curso e alinhados ao conteúdo básico de Matemática Financeira.

Miron (2013) desenvolveu em sua Dissertação um conjunto de situações-problema, com a finalidade de investigar aspectos referentes ao ensino e aprendizagem de Matemática Financeira em uma turma de Educação de Jovens e Adultos (EJA), para tal embasou-se na metodologia da Resolução de Problemas. Após a análise dos dados identificou-se uma dificuldade por parte dos alunos com relação a interpretação dos enunciados, a autora concluiu ainda que com o desenvolvimento das atividades os alunos adquiriram uma maior autonomia na construção do seu próprio conhecimento.

Pereira (2014) propõe em seu produto educacional utilizar o fluxo de caixa pessoal para educar financeiramente a sociedade. Afirma assim ter a pretensão de estimular nos estudantes e seus familiares o hábito de contabilizar seus gastos diários ao consumir produtos e, ou, serviços realizando uma análise e promovendo sua autonomia financeira. Sugere ainda a criação de um guia didático para a proposta.

Não obstante, no trabalho de Vital (2014) o autor apresenta um conjunto de tarefas elaboradas com a finalidade de provocar na sala de aula um ambiente capaz 
de estimular os alunos a analisar e a discutir sobre um importante tema em nossa sociedade: a inflação de preços, utilizando de conceitos de Matemática Financeira, podendo contribuir economicamente com a sociedade.

Jover (2014) demonstra em seu trabalho a importância da utilização de jogos com o objetivo de educar financeiramente os alunos. Relata ainda a importância social do Professor de Matemática Financeira e diz que este ofício deve ser divertido, desafiador, e proporcionar o pensamento reflexivo dos alunos.

Almeida (2015) sugere em seu trabalho uma reflexão com professores sobre o significado de educar financeiramente os alunos, sempre partindo do pressuposto do que é realmente relevante neste processo. Por meio de um caderno de atividades, identificou que quando a Matemática Financeira é aplicada no cotidiano, o que foi aprendido em sala de aula deve ser realmente colocado em prática.

Na Dissertação de Cargnin (2015), a autora desenvolveu uma Sequência de Atividades para trabalhar com alunos da Educação de Jovens e Adultos (EJA) situações financeiras reais, para tal a autora utilizou-se da metodologia da Resolução de Problemas, bem como a utilização de computadores com vista a propiciar aos alunos recursos diferenciados de modo a motiva-los e incentivar a inclusão digital. Após a implementação das atividades a autora identificou que foi possível uma reflexão crítica por parte dos alunos, o que oportunizou uma mudança com relação a hábitos referentes ao controle de finanças, como planejamento, consumo e investimento.

O trabalho de Costa (2015) trata da Matemática Financeira tendo em suas intenções, proporcionar aos estudantes por meio de um Minicurso, a emersão em caráter reflexivo, matemático, financeiro e crítico, pois atrelados aos recursos tecnológicos (calculadora e computador), um aluno terá condições de apoderar-se de seus conhecimentos advindos do meio escolar e de mundo, a fim de conjecturar sobre possíveis caminhos.

Já Costa (2015), aponta em seu trabalho a importância da educação financeira no contexto escolar, propondo um curso de Educação em Matemática Financeira promovendo didaticamente contribuições construtivistas partindo do pressuposto da ciência e tecnologia.

De acordo com Dias (2015), apresenta um conjunto de tarefas elaboradas com a finalidade de criar na sala de aula um ambiente capaz de estimular os alunos a analisar e a discutir sobre um importante tema em Educação Financeira na escola: 
a noção de juros, acrescentando ainda a importância desse conceito para a evolução do conteúdo em sala de aula.

Oliveira (2015) traz em sua Dissertação uma abordagem de conceitos tangentes a Matemática Financeira, como juros, acréscimos, descontos, entre outros, porém trabalhando na Educação Básica conteúdos como Amortizações, Financiamentos com prestações fixas, entre outros, e que em sua grande maioria são trabalhados somente em cursos que envolvem finanças, como Administração, Contabilidade e Economia. Cabe ainda destacar que foram utilizadas a calculadora "simples, a científica e a "calculadora do cidadão" do Banco Central.

Em seu trabalho, Santos (2015) sugere a criação de uma cartilha que aborde conteúdos de Matemática Financeira, construindo conceitos baseando-se em tabelas de amortização. Sugerindo ainda a utilização de exemplos práticos como o financiamento de veículos.

A Dissertação de Gadotti (2016) objetivou aplicar com alunos da Educação Básica de escolas públicas atividades acerca da Educação Financeira e que foram desenvolvidas com base em dados reais, visando preceitos de um consumo sustentável e uma vida financeira consciente por parte dos estudantes.

De acordo com Gimenes (2016) uma sequência didática elaborada para ensinar Matemática Financeira pode proporcionar aos mesmos a oportunidade de serem protagonistas na tomada de decisões na esfera financeira, gerando aprendizado significativo proporcionando aos alunos a capacidade plena de aplicar conceitos.

Lima (2016) desenvolveu um ambiente virtual para o trabalho com a Educação Financeira denominado SpigMath, neste ambiente a autora desenvolveu atividades de Educação Financeira e que contemplem os conteúdos previsto para o Ensino Fundamental.

Já no trabalho de Martins (2016), identifica-se o uso de calculadoras e planilhas eletrônicas para ensinar Matemática Financeira por meio de uma Sequência Didática, utilizando conteúdos básicos, como juros simples e juros compostos. Evidenciou-se neste trabalho que quando a sociedade está preparada para consumir de forma consciente, nota-se a existência de capacidade cognitiva para avaliar tanto o processo de compra e venda, quanto dos juros que estão dispostos e preparados a pagar, bem como a coerência entre o valor dos produtos apresentado nas propagandas e o valor efetivamente aplicado. $O$ trabalho ainda demonstrou que os alunos envolvidos nesta pesquisa, tiveram melhores resultados ao utilizarem a calculadora HP 12C. 
No trabalho de Oliveira (2016), apresenta-se uma proposta sobre a prática dentro das aulas de Vivências de Educação Financeira, como parte do projeto pedagógico para uma educação de tempo integral da rede SESI - SP, com um olhar de pesquisador das atividades propostas aos alunos.

Pinheiro (2016) desenvolveu em seu trabalho um produto baseado em um conjunto de tarefas que tinham como objetivo ensinar conceitos relacionados à tributação e a importância dela no contexto econômico. Como resultado, a aplicação desse produto contribuiu para a formação econômica desses alunos.

A produção de Raschen (2016) apresenta resultados referentes a aplicação de duas atividades com alunos do segundo ano do Ensino Médio, que visou identificar as contribuições da Matemática para o trabalho com a Educação Financeira em âmbito escolar.

Silva (2016) argumenta que um conjunto de atividades elaboradas com o intuito de ensinar Matemática Financeira, pode contribuir para a educação financeira dos alunos. Argumenta ainda que a utilização de recursos tecnológicos nesse processo pode aperfeiçoar os ganhos no ensino.

Neste contexto, Teixeira (2016) relata ter elaborado um produto educacional, baseando-se nas observações feitas em sala de aula e a necessidade em se abordar temas relacionados à educação financeira, que tinham como pano de fundo os conceitos e conteúdos de Matemática Financeira.

Santos (2017) em seu trabalho fala de um guia de atividades como um projeto pedagógico para ensinar matemática financeira de uma forma transdisciplinar. As atividades relacionam conteúdos de Matemática Financeira com situações cotidianas do mercado consumidor como, compras, empréstimos, financiamentos, entre outros.

De acordo com o trabalho de Silva (2017), a cada momento o professor deve reinventar a sua forma de ensinar, adicionando novas metodologias que prendam a atenção do aluno de uma forma bem divertida. Fazendo uma análise do produto foi possível perceber que ele envolve estratégias de ensino, a criação de um jogo educacional trazendo noções de Educação Financeira e conceitos relacionados à sustentabilidade, desigualdade social, ética, desperdícios, entre outros. O jogo é dinâmico, interativo, sendo que em cada uma das fases o objetivo é bem claro e o participante recebe "dinheiro ilustrativo" para estimular o entendimento do processo. O conteúdo de Matemática Financeira abordado é o básico, analisando variáveis como juros, valor futuro e presente de um capital, entre outros. 
Silva (2017) propôs em seu trabalho a criação de um Ebook como produto educacional, trabalhando a Matemática Financeira como foco na educação financeira. Uma das preocupações que nortearam o desenvolvimento dos conteúdos foi apresentar a Matemática Financeira de maneira contextualizada, trazendo questões do seu cotidiano, com as quais você pudesse se identificar, favorecendo a aplicação das aprendizagens desenvolvidas na sala de aula, em seu dia a dia. Para tanto, organizou atividades de pesquisa que poderão ser desenvolvidas individualmente ou em pequenos grupos. Analise e interprete os fatos e as ideias, troque informações com seus colegas e o professor.

A Dissertação de Villa (2017) tem como intuito apresentar uma Sequência Didática para o ensino de Educação Financeira Ensino Médio, batizada pela teoria da Aprendizagem Significativa de Ausubel e com a utilização do software Excel. Esta produção foi implementada em uma turma do segundo ano do Ensino Médio, e após a análise dos dados foi constatado que os alunos já consideravam a temática como potencialmente significativa, porém detinham conceitos incompletos ou equivocados com relação a Educação Financeira. Cabe destacar ainda, que o autor identificou indícios da aprendizagem significativa.

No trabalho de Argôlo (2018) o autor visa por meio de uma Sequência de Atividades abordar o planejamento financeiro, tendo como base os preceitos da Educação Financeira. Tais atividades foram desenvolvidas com os alunos do terceiro ano de um curso técnico em informática, e tiveram como resultados um avanço no que tange ao planejamento financeiro dos estudantes, bem como na motivação para com o processo de ensino e aprendizagem.

A Dissertação de Jacobsen (2018) visou evidenciar as potencialidades da implementação de uma Unidade de Ensino e Aprendizagem Gamificada por meio da plataforma Moodle, com vistas ao ensino e aprendizagem de conceitos de Matemática Financeira. Um dos resultados a destacar-se de acordo com a autora é que a utilização do Moodle para utilização de técnicas de Gamificação serviu como ferramenta para motivação dos alunos nas resoluções das atividades.

Já Lovatti (2018) apresenta uma proposta com objetivo de instruir sobre a importância de ensinar o conteúdo de matemática financeira de uma forma diferenciada onde os alunos terão maior participação no processo de ensino e aprendizagem deixando de ser apenas repetidores de técnicas de resolução de exercícios e tornando-se alunos com uma competência crítica acerca dos assuntos voltados para 
as finanças. Um conjunto de atividades foi pensada de forma a criar um ambiente que se aproxime de um cenário para investigação, com problemas que estimulam 0 raciocínio e discussões entre os participantes do estudo e que também são próximos aos problemas encontrados no dia a dia.

Muniz (2018) elaborou um produto educacional sendo um Conjunto de Atividades de Educação Financeira para o Ensino. Durante esta pesquisa foi possível constatar a emergência que há de se elaborar um conjunto de tarefas que possa favorecer os procedimentos em sala de aula com relação à Educação Financeira. Sabemos que se trata sempre de um tema atual, tal como já é apontado nos parâmetros curriculares Nacionais (1999).

Sodré (2018) trabalha em sua pesquisa um produto educacional materializado por meio de uma sequência didática sobre juros compostos que foi desenvolvida baseada na Teoria das Situações Didáticas de Guy Brousseau, com o objetivo de ajudar a formação em educação financeira de um grupo de alunos do $1^{0}$ ano do Ensino Médio de uma escola da rede privada de ensino de Contagem (MG). Dessa forma, o objetivo desse produto educacional não só sugere uma sequência de atividades graduadas para se trabalhar e discutir o conceito de juros compostos com foco na Educação Financeira, como também propõe a reflexão para abordar outros conceitos da Educação Financeira, tão importantes quanto esse, e que devem ser trabalhados com alunos em todos os anos da Escola Básica.

Sobreira (2018) apresenta os resultados de uma pesquisa que teve como meta investigar a viabilidade do ensino dos temas abordados na Matemática Financeira da educação básica por meio de atividades desenvolvidas através de uma sequência didática, diferente da tradicional, que privilegia os aspectos práticos do financiamento sobre a participação e desempenho da resolução de questões, a partir de situações-problema mediadas por uma calculadora.

Continuando a análise, o trabalho de Casado (2019) trata da criação de uma Sequência Didática para ensinar Matemática Financeira na Educação de Jovens e Adultos. A Sequência Didática, que foi bem estruturada contextualizando de forma clara situações cotidianas como o planejamento para uma compra a vista ou a prazo, corroborando com a vivência de cada um, promovendo atividades investigativas alinhadas a vertente financeira.

A Dissertação de Dias (2019) visou desenvolver um material textual de apoio aos docentes, para o trabalho com a Matemática Financeira no curso de Educação 
de Jovens e Adultos (EJA), embasada na teoria da Aprendizagem Significativa. A autora ainda destaca que este material pode ampliar os conhecimentos dos discentes com relação às finanças, de modo a contribuir com a Educação Financeira.

Ferreira (2019) fez uma pesquisa com o objetivo de compreender de que maneira a disciplina de Matemática Financeira está estruturada nos Projetos Pedagógicos dos Cursos (PPCs) dos cursos de licenciatura em Matemática e adequada à futura prática docente dos licenciados. Propôs-se então como produto educacional a realização de um curso de formação continuada para professores de uma escola pública municipal de ensino da cidade de Rio Verde/GO, com propósito de preencher a lacuna que existia na formação desses professores, em relação ao trabalho direcionado à Matemática Financeira, numa perspectiva de Educação Financeira.

Na Dissertação de Moraes (2019) a autora visa apresentar as possíveis associações que os discentes desenvolvem com relação a Educação Financeira em aulas de Matemática Financeira no Ensino Médio. Para tal, foi desenvolvida uma Sequência Didática à luz da Engenharia Didática com alunos de três turmas do terceiro ano do Ensino Médio. Assim, com a análise dos dados obtidos foi constatado pela autora que este trabalho é de fundamental importância para que os discentes adquiram conhecimentos para terem uma vida financeira estável.

Tem-se que na produção de Rossetto (2019) foi desenvolvida uma Sequência de Atividades com alunos do segundo ano de uma turma da Educação de Jovens e Adultos (EJA) na qual teve como finalidade incluir a temática da Educação Financeira neste contexto da Educação Básica. Como resultados o autor identificou que uma pequena parcela dos alunos possuía o controle dos seus gastos e despesas, sendo alguns até analfabetos financeiros. Outro fator a destacar-se é que após a implementação das atividades o autor constatou as contribuições da Matemática para a solução de situações-problema que envolvem finanças.

A Dissertação de Schneider (2019) é oriunda das inquietações do próprio autor e dos discursos de alguns colegas acerca da preparação dos jovens para a vivência em uma sociedade capitalista, a qual constantemente deparam-se com crises financeiras. Assim, o autor desenvolveu uma Sequência de Atividades para trabalhar conceitos de Educação Financeira com alunos do primeiro ano do Ensino Médio de uma escola pública. Como resultados o autor destaca que o aprimoramento das tomadas de decisão no que refere-se as finanças, evidenciando ainda uma diferenciação por parte dos alunos no que refere-se a necessidades, desejo e bem-estar. 
O trabalho de Souza (2019) investigou a prática da educação financeira optando-se pelos métodos da pesquisa-ação no sentido de que o processo investigativo da prática pedagógica pudesse auxiliar na sistematização e planejamento das atividades didáticas desenvolvidas no decorrer do processo investigativo. Para isso, utilizou-se da sequência didática como procedimento sistematizador do processo assistemático de educação financeira, que já era desenvolvido pela professora antes da formação continuada.

Por fim, temos a Dissertação de Dias (2020), que ainda não encontra-se disponível para download no site do Programa de Pós-graduação a qual foi desenvolvida. Porém cabe destacar que pelo título é possível identificar que a mesma abordará a Matemática Financeira por meio de uma Sequência Didática.

Em síntese fica evidente que os trabalhos desenvolvidos nos Programas de Mestrado Profissional em Ensino trazem a mesma preocupação das indagações primárias dessa pesquisa, que é saber quais Produtos Educacionais estão sendo criados para ensinar Matemática Financeira e/ ou Educação Financeira. No entanto nota-se um número restrito de trabalhos que abordam a temática, deixando claro que essa lacuna deve ser preenchida levando em consideração a função social dessas pesquisas. Quando se fala em função social trata-se do sentido de capacitar os alunos a serem consumidores conscientes, tomando decisões adequadas em relação a compra e venda de bens e serviços, sabendo assim administrar suas próprias finanças, de forma simples e ágil, utilizando de recursos pedagógicos disponíveis (SKOVSMOSE 2008, apud LIMA; SÁ, 2010, p. 35).

Levando em consideração as premissas econômicas da sociedade, a escassez de recursos e ainda o paradoxo envolvendo a disponibilidade de recursos versus a capacidade de compra dos indivíduos, discutir a melhor forma de se comprar, a melhor forma de investir seu capital e ainda minimizar o pagamento de juros é totalmente pertinente e necessário na formação dos alunos e futuros cidadãos. Sendo assim o professor tem papel fundamental junto a seus alunos, preparando-os para que sejam consumidores mais conscientes, podendo contribuir com o processo de formação de renda e poupança, fatores esses que podem promover o desenvolvimento de um país. 


\section{Considerações finais}

Com a pesquisa realizada a luz da Revisão Sistemática da Literatura, tornou-se possível perceber que existe um restrito número de Programas de Mestrado Profissional em Ensino, que realizaram pesquisas e Produtos Educacionais voltados ao ensino de Matemática Financeira e/ ou Educação Financeira. No entanto, dentre as informações investigadas e demonstradas nos quadros, relatamos aquelas que buscam responder a "Q1: Quantas e quais são as Dissertações (de Mestrados Profissionais em Ensino) que abordam a Matemática Financeira e / ou Educação Financeira como temática central?” Após a análise dos Produtos Educacionais identificou-se que apenas, 45 trabalhos, ou seja, 1,04\% dos trabalhos pesquisados dizem respeito à temática desta pesquisa.

Já abordando a pesquisa a luz da argumentação da "Q2: De que forma o conteúdo de Matemática Financeira é abordado nestas Dissertações?”, neste contexto, 45 trabalhos, ou seja, $100 \%$ da amostra utilizam o conteúdo de Matemática Financeira atrelados a situações cotidianas dos alunos como, por exemplo, compra e venda de produtos, financiamentos, empréstimos, entre outras atividades que podem propiciar que estes se tornem consumidores mais conscientes. Neste contexto, quando se prepara alunos com o intuito de torna-los consumidores conscientes, entra em cena o "educar financeiramente". Percebe-se que todos os trabalhos aqui analisados tratam do ensino de Matemática Financeira com esse propósito, atrelando as duas temáticas.

Reportando a pesquisa para quais produtos educacionais estão sendo criados a "Q3: Quais metodologias e recursos estão sendo utilizados ao trabalhar-se com a Matemática Financeira?”, temos que 22,22\% (10 trabalhos) das produções trazem a Sequência Didática como Produto Educacional, 33,33\% (15 trabalhos) criaram um conjunto de atividades ou Sequência de Atividades, $11,11 \%$ (5 trabalhos) desenvolveram um curso ou um minicurso relacionado a temática, 6,66\% (3 trabalhos) dos trabalhos tratam de um Guia Didático, 4,4\% (2 trabalhos) Jogos Educacionais e o restante (10 trabalhos) estão divididos entre Cartilhas, Coletânea de Estudos, Material Textual de Apoio, Livretos, E-books, Planilhas Eletrônicas, Proposta Metodológica de Ensino, Ambiente Virtual, Tutorial para o uso da calculadora HP 12C, Unidade de Ensino e Aprendizagem (UEA) Gamificada. 
Cabe ainda destacar que em diversos trabalhos, como os de Rodrigues Filho (2012), Costa (2015), Oliveira (2015), Falcão Neto (2016), Martins (2016) e Sobreira (2018), os autores utilizaram algum Recurso Tecnológico no desenvolvimento do seu Produto Educacional, à citar: a calculadoras, como por exemplo, a calculadora HP 12C, a calculadora científica e a calculadora "simples", as Planilhas Eletrônicas como o software Excel.

Em síntese, o estudo desenvolvido nesta Revisão Sistemática de Literatura, fez um levantamento de trabalhos que abordam o ensino de Matemática Financeira e a contribuição disso para o processo de ensino e a formação de consumidores conscientes e cidadãos preparados para a análise de situações financeiras cotidianas. Neste contexto, para encaminhamentos futuros, pretende-se desenvolver uma pesquisa que aborde a temática de Matemática Financeira, utilizando recursos midiáticos ou desenvolvendo ações, a fim de suprir esta lacuna.

\section{Financial Mathematics in the Professional Master in Teaching: a Literature Review}

\section{Abstract}

This paper aims to identify which Educational Products are being produced in Professional Master's Degrees in Teaching involving Mathematics and Financial Education and also which methodologies and resources are being used for teaching these contents. This research assumes a qualitative and procedural bibliographic nature, using an adaptation of the steps of the Systematic Literature Review and consulting the online repositories of the respective Professional Master in Teaching programs evaluated by Coordination for the Improvement of Higher Education Personnel in the 2017 quadrennium. After the analysis, it was possible to identify that among the 4.417 initial works, only 45 dealt with the theme researched, which represents approximately $1.04 \%$ of the total. Another factor identified was that the content of Financial Mathematics is presented linked to the daily situations of students, referring to the purchase and sale of products, financing, loans, and other activities, allowing them to experience situations that make them more aware consumers. In the end, $22.22 \%$ (10 works) of the productions bring the Didactic Sequence as an Educational Product, 33.33\% (15 works) created a set of activities or Sequence of Activities, $11.11 \%$ (5 works) developed a course or a minicourse related to the theme, $6.66 \%$ (3 works) of the works deal with a Didactic Guide, 4.4\% (2 works) Educational Games and the rest (10 works) are divided between Primers, Collection of Studies, Textual Support Material, Booklets, E-books, Electronic Spreadsheets, Teaching Methodology Proposal, Virtual Environment, Tutorial for using the HP 12C calculator, Teaching and Learning Gamified Unit.

Keywords: Teaching; Professional Master's Degrees; Financial Education; Financial Mathematics; Systematic Literature Review. 
ALMEIDA, Rodrigo Martins de. $O$ movimento das pesquisas em educação matemática financeira escolar de 1999 a 2005. Juiz de Fora: UFJF, 2015. Dissertação, Instituto de ciências exatas, Universidade Federal de Juiz de Fora, 2015.

ARGÔLO, Patrícia Santana de. Educação financeira na sala de aula: uma proposta metodológica para o ensino da Matemática no Ensino Médio. Lajeado: UNIVATES, 2018. Dissertação, Curso de Ensino de Ciências Exatas, Universidade do Vale do Taquari, 2018.

BARROSO, Dejair Frank. Uma proposta de curso de serviço para a disciplina matemática financeira: mediada pela produção de significados dos estudantes de administração. Juiz de Fora: UFJF, 2013. Dissertação, Instituto de ciências exatas, Universidade Federal de Juiz de Fora, 2013.

BRASIL. Decreto de lei 7.397, de 22 de dezembro de 2010. Institui a Estratégia Nacional de Educação Financeira - ENEF. Diário Oficial da República Federativa do Brasil, Brasília, 23 de dezembro de 2010. Seção 1, p. 7. Disponível em: <http://www.planalto.gov.br/ccivil_03/_Ato20072010/2010/Decreto/D7397.htm>. Acesso em: 21 maio 2020.

CAPES. Coordenação de Aperfeiçoamento de Pessoal de Nível Superior. Mestrado no Brasil a situação e uma nova perspectiva. Infocapes, v. 3, n. 3-4, p. 18-21, 1995.

CAPES. Coordenação de Aperfeiçoamento de Pessoal de Nível Superior. Resultados finais da avaliação quadrienal 2017 - programas profissionais. 2017. Disponível em: < https://www. capes.gov.br/36-noticias/8691-capes-divulga-resultado-final-da-avaliacao-quadrienal-2017 >. Acesso em: 20 jun 2019.

CARGNIN, Rita Maria. Matemática financeira na educação de jovens e adultos: uma proposta de ensino através da resolução de problemas. Santa Maria: UFN, 2015. Dissertação, Mestrado Profissionalizante em Ensino de Física e Matemática, Centro Universitário Franciscano, 2015.

CASADO, Wellison Gomes. A matemática financeira na Educação de Jovens e Adultos: possibilidades de ensino e aprendizagem. Campo Grande: UEPB, 2019. Dissertação, Mestrado Profissional em Ensino de Ciências e Educação Matemática, Universidade Estadual da Paraíba, 2019.

CÓSER FILHO, Marcelo Salvador. Aprendizagem de matemática financeira no ensino médio: uma proposta de trabalho a partir de planilhas eletrônicas. Porto Alegre: UFRGS, 2008. Dissertação, Instituto de Matemática, Universidade Federal do Rio Grande do Sul, 2008.

COSTA, Ana Luiza Araujo. Matemática financeira e cidadania: interlocução, leituras e experiências. Campina Grande: UEPB, 2015. Dissertação, Programa de Pós-Graduação em Ensino de Ciências e Educação Matemática, Universidade Estadual da Paraíba, 2015.

COSTA, Luciano Pecoraro. Matemática financeira e tecnologia: espaços para o desenvolvimento da capacidade crítica dos educandos da educação de jovens e adultos. Juiz de Fora: UFJF, 2015. Dissertação, Instituto de Ciências Exatas, Universidade Federal de Juiz de Fora, 2015.

DIAS, Jesus Nazareno Martins. Educação financeira escolar: a noção de juros. Juiz de Fora: UFJF, 2015. Dissertação, Instituto de Ciências Exatas, Universidade Federal de Juiz de Fora, 2015.

DIAS, Lorena Silva de Andrade. Funções executivas, matemática financeira e previdência social: sequência didática para formação inicial docente. Florianópolis: UDESC, 2020. Dissertação, 
Programa de Pós-Graduação em Ensino de Ciências, Matemática e Tecnologias, Universidade do Estado de Santa Catarina, 2020.

DIAS, Rosa Cristina Vieira. A matemática financeira e a aprendizagem significativa - possíveis contribuições à educação de jovens e adultos. Santos: UNIMES, 2019. Dissertação, Mestrado Profissional de Práticas Docentes no Ensino Fundamental, Universidade Metropolitana de Santos, 2019.

FALCÃO NETO, Antônio. O uso da calculadora HP-12C nas operações de matemática financeira comercial com ênfase na análise de investimento. Fortaleza: UFC, 2011. Dissertação, Mestrado Profissional em Ensino de Ciências e Matemática, Universidade Federal do Ceará, 2011.

FARIAS, Gisele Valle. A Matemática Financeira na Educação Básica e sua importância para a formação do cidadão consciente. Rio de Janeiro: UFRJ, 2013. Dissertação, Mestrado Profissional em Matemática, Universidade Federal do Rio de Janeiro, 2013.

FELIZARDO, Katia Romero; NAKAGAWA, Elisa Yumi; FABBRI, Sandra Camargo Pinto Ferraz; FERRARI, Fabiano Cutigi. Revisão Sistemática. In: FELIZARDO, Katia Romero; NAKAGAWA, Elisa Yumi; FABBRI, Sandra Camargo Pinto Ferraz; FERRARI, Fabiano Cutigi. Revisão sistemática da literatura em engenharia de software: teoria e prática. Rio de Janeiro: Elsevier, 2017.

FERREIRA, Regimar Alves. A disciplina de Matemática Financeira nas licenciaturas em Matemática e uma proposta de formação continuada na perspectiva da Matemática Crítica. Jataí: IFG, 2019. Dissertação, Programa de Pós-Graduação em Educação para Ciências e Matemática, Instituto Federal de Goiás, 2019.

FLICK, Uwe. Introdução à pesquisa qualitativa. Tradução: Joice Elias Costa. 3. ed. Porto Alegre: Artmed, 2009. Título original: Qualitative sozialforschung.

GADOTTI, Ana Carolina. Educação financeira por meio de dados reais: atividades didáticas para a educação básica. Blumenau: FURB, 2016. Dissertação, Programa de Pós-Graduação em Ensino de Ciências Naturais e Matemática, Universidade Regional de Blumenau, 2016.

GIMENES, Deivid Geraldo. Construção de uma sequência didática com situações-problema envolvendo matemática financeira. São Carlos: UFSCAR, 2016. Dissertação, Centro de Ciências Exatas e de Tecnologia, Universidade Federal de São Carlos, São Carlos, 2016.

GONÇALVES, Rafael Alberto. Introdução à matemática financeira por meio de planilhas eletrônicas. Blumenau: FURB, 2012. Dissertação, Programa de Pós-Graduação em Ensino de Ciências Naturais e Matemática, Universidade Regional de Blumenau, 2012.

JACOBSEN, Daniela de Melo. Contribuições da gamificação para o ensino e a aprendizagem: uma proposta de ensino para matemática financeira. Santa Maria: UFN, 2018. Dissertação, Programa de Pós-Graduação em Ensino de Ciências e Matemática, Universidade Franciscana, 2018.

JOVER, Renato Schneider Rivero. Matemática financeira no ensino médio: um jogo para simulação. Porto Alegre: UFRGS, 2014. Dissertação, Programa de Pós-Graduação em Ensino de Matemática, Universidade Federal do Rio Grande do Sul, 2014.

KERN, Denise Teresinha Brandão. Uma reflexão sobre a importância de inclusão de Educação Financeira na escola pública. Lajeado: UNIVATES, 2009. Dissertação, Curso de Ensino de Ciências Exatas, Universidade do Vale do Taquari, 2009. 
LIMA, Adriana de Souza. Educação Financeira no Ensino Fundamental: um bom negócio. Rio de Janeiro: CPII, 2016. Dissertação, Mestrado Profissional em Práticas em Educação Básica, Colégio Pedro II, 2016.

LIMA, Cristiane Bahia; SÁ, Ilydio Pereira de. Matemática Financeira no Ensino Fundamental. Revista TECCEN, v.3, n. 1, p. 34-43, abr. 2010.

LOVATTI, Flávia Arlete. A educação matemática crítica na educação financeira. Vitória: IFES, 2018. Dissertação, Programa de Pós-Graduação em Educação em Ciências e Matemática, Instituto Federal do Espirito Santo, 2018.

MARQUES, Claiton Regis Timm. Uso de tecnologias da informação para a aprendizagem de matemática financeira em cursos técnicos. Santa Maria: UFN, 2010. Dissertação, Mestrado em Ensino de Matemática, Universidade Franciscana, 2010.

MARTINS, Iomara de Albuquerque Madeira. Utilização de práticas pedagógicas diferenciadas no ensino de matemática financeira: um estudo de caso no instituto maranhense de ensino e cultura - IMEC. 2016. Lajeado: UNIVATES, 2016. Dissertação, Programa de Pós-Graduação Stricto Sensu, Centro Universitário UNIVATES, 2016.

MIRON, Tatiele Fátima. Metodologia de resolução de problemas: ensino e aprendizagem de conceitos de matemática financeira no EJA. Santa Maria: UFN, 2013. Dissertação, Mestrado em Ensino de Matemática, Universidade Franciscana, 2013.

MORAES, Aline Reissuy de. Educação financeira no ensino médio: uma proposta para as aulas de matemática. Passo Fundo: UPF, 2019. Dissertação, Mestrado em Ensino de Ciências e Matemática, Universidade de Passo Fundo, 2019.

MOREIRA, Marco Antonio. O mestrado (profissional) em ensino. Revista Brasileira da Pós-Graduação, v. 1, n. 1, p. 131-142, jul. 2004.

MOREIRA, Marco Antonio. Os mestrados profissionais nacionais, enquanto política pública, representam um grande avanço para a educação brasileira. [Entrevista concedida a] Luiza Oliveira. Polyphonía, v. 26, n.1, p. 244-249, 2015.

MUNIZ, Carlos Magno Oliveira. Educação de jovens e adultos (eja) e saberes matemáticos sob a perspectiva da educação financeira escolar. Duque de Caxias: UNIGRANRIO, 2018. Dissertação, Programa de Pós-Graduação em Ensino das Ciências, Universidade do Grande Rio, 2018.

OLIVEIRA, Bruno Henrique de. Matemática Financeira no Ensino Médio: Uma Proposta Metodológica de Ensino. São Carlos: UFSCAR, 2015. Dissertação, Programa de Pós-Graduação em Ensino de Ciências Exatas, Universidade Federal de São Carlos, 2015.

OLIVEIRA, Juliana Bauer de. Atividades de matemática financeira por meio de aprendizagem coletiva nos anos finais do ensino fundamental. São Carlos: UFSCAR, 2016. Dissertação, Centro de Ciências Exatas e Tecnologia, Universidade Federal de São Carlos, 2016.

PEREIRA, Alexsandra Alves. Fluxo de caixa: educação financeira em aulas de matemática com estudantes do ensino médio de uma escola do interior do Espírito Santo. Vitória: IFES, 2014. Dissertação, Programa de Pós-Graduação em Educação em Ciências e Matemática, Instituto Federal do Espírito Santo, 2014. 
PINHEIRO, Cláudio Júlio César. Contribuições da matemática financeira para o ensino médio: o uso de tributos em tarefas de sala de aula. Sorocaba: UFSCAR, 2016. Dissertação, Centro de Ciências Exatas e Tecnologia, Universidade Federal de São Carlos, 2016.

RASCHEN, Samuel Ricardo. Investigação sobre as contribuições da matemática para o desenvolvimento da educação financeira na escola. Porto Alegre: UFRGS, 2016. Dissertação, Programa de Pós-Graduação em Ensino de Matemática, Universidade Federal do Rio Grande do Sul, 2016.

REBEQUE, Paulo Vinicius; OSTERMANN, Fernanda; VISEU, Sofia. Os Mestrados Profissionais em Ensino de Ciências e Matemática no Brasil: um tema pouco explorado na literatura. Revista Brasileira de Ensino de Ciência e Tecnologia, Ponta Grossa, v. 10, n. 2, p. 1-21, maio/ ago. 2017.

ROCHA, Angela Joanella Cardoso; MARIANI, Rita de Cássia Pistóia. Tomada de decisão diante de situações econômico-financeiras: educação financeira escolar e representações semióticas mobilizadas por licenciandos em Matemática. Revista Brasileira de Ensino de Ciências e Matemática, Passo Fundo, v. 2, n. 2, p. 225-252, jul./ dez. 2019.

RODRIGUES FILHO, Newton. Tecnologias informacionais e comunicacionais na educação matemática financeira: criando cenários de investigação na licenciatura em matemática. Ouro Preto: UFOP, 2012. Dissertação, Instituto de Ciências Exatas e Biológicas, Universidade Federal de Ouro Preto, 2012.

ROSSETTO, Júlio César. Educação financeira crítica: a gestão do orçamento familiar por meio de uma prática pedagógica na educação de jovens e adultos. Lajeado: UNIVATES, 2019. Dissertação, Curso de Ensino de Ciências Exatas, Universidade do Vale do Taquari, 2019.

SANTOS, Jackelinne Azevedo Silva dos. Matemática financeira no ensino médio numa perspectiva investigativa. Vitória: IFES, 2015. Dissertação, Programa de Pós-Graduação em Educação em Ciências e Matemática, Instituto Federal do Espiríto Santo, 2015.

SANTOS, Leandro Gonçalves dos. Educação financeira e educação matemática: inflação de preços no ensino médio. Juiz de Fora: UFJF, 2017. Dissertação, Programa de Pós-Graduação em Educação Matemática, Universidade Federal de Juiz de Fora, 2017.

SCHNEIDER, Tcharles. Educação financeira: investigação com uma turma de 1⿳亠丷a ano do Ensino Médio por meio de práticas colaborativas. Lajeado: UNIVATES, 2019. Dissertação, Curso de Ensino de Ciências Exatas, Universidade do Vale do Taquari, 2019.

SILVA, Edna Lúcia; MENEZES, Eestera Muszkat. Metodologia da pesquisa e elaboração de dissertação. 4. ed. Florianópolis: UFSC, 2005.

SILVA, Iran Abib Valente da. O uso do dinheiro como recurso sustentável: uma reflexão para a educação financeira cidadã. Belém: UFPA, 2017. Dissertação, Instituto de Educação Matemática e Científica, Universidade Federal do Pará, 2017.

SILVA, Rudney da. Educação de matemática financeira no ensino médio: uma análise crítica do custo de vida. Vitória: IFES, 2016. Dissertação, Programa de Pósgraduação em Educação em Ciências e Matemática, Instituto Federal do Espirito Santo, 2016.

SILVA, Marisa do Carmo Pacoff da. Noções de matemática financeira com foco em educação financeira. Santo Ângelo: URI, 2017. Dissertação, Pós-Graduação em Ensino Científico e Tecnológico, Universidade Regional Integrada do Alto Uruguai e das Missões, 2017. 
SOBREIRA, André Alves. O ensino de matemática financeira e aplicações. Belém: UEPA, 2018. Dissertação, Programa de Mestrado Profissional em Ensino de Matemática, Universidade do Estado Pará, 2018.

SODRÉ, Aline Amanda Sousa Lopes. Investigando uma sequência didática sobre juros compostos para a formação em educação financeira de alunos do ensino médio. Ouro Preto: UFOP, 2018. Dissertação, Instituto de Ciências Exatas e Biológicas, Universidade Federal de Ouro Preto, 2018.

SOUZA, Sílvia Helena da Silva e. Educação financeira: olhar sobre a prática do professor que ensina matemática nos anos iniciais do ensino fundamental. Belém: UFPA, 2019. Dissertação, Mestrado Profissional em Docência em Educação em Ciências e Matemáticas, Universidade Federal do Pará, 2019.

TEIXEIRA, Wesley Carminati. A inserção da educação financeira em um curso de serviço de matemática financeira para graduandos de administração. Juiz de Fora: UFJF, 2016. Dissertação, Programa de Pós-Graduação Stricto Sensu, Universidade Federal de Juiz de Fora, 2016.

VILLA, Laercio. Educação financeira no Ensino Médio: uma análise a partir da Aprendizagem Significativa de David Ausubel. Passo Fundo: UPF, 2017. Dissertação, Mestrado em Ensino de Ciências e Matemática, Universidade de Passo Fundo, 2017.

VITAL, Márcio Carlos. Educação financeira e educação matemática: inflação de preços. Juiz de Fora: UFJF, 2014. Dissertação, Pós-Graduação em Educação Matemática, Universidade Federal de Juiz de Fora, 2014. 